\title{
The Evaluation of Cultural Differences on the Identity of the Window Display: The Case Study of the Perception of British and Thai Consumers
}

\author{
Kanokwan Somoon ${ }^{1} \&$ Chumporn Moorapun ${ }^{2}$ \\ ${ }^{1}$ Faculty of Architecture, King Mongkut's Institute of Technology Ladkrabang, Bangkok, Thailand \\ Correspondence: Kanokwan Somoon, Multidisciplinary Design Research Program, Faculty of Architecture, King \\ Mongkut's Institute of Technology Ladkrabang, Bangkok, Thailand 10520. E-mail: Kanokwan.oily@gmail.com
}

Received: August 24, 2017

doi:10.5539/ass.v13n11p71
Accepted: October 2, $2017 \quad$ Online Published: October 28, 2017

URL: https://doi.org/10.5539/ass.v13n11p71

\begin{abstract}
Window display is a marketing tool for products presentation and sale promotion as well as product image promotion. There are some researches that tried to describe relationship between consumer behavior and window display design by using marketing concept and psychologically acknowledge but they are not involve to cross culture. However, consumer's perception depends on their background, experience and cultural factor. Our research attempts to evaluate the cross culture consumer perception on window display identity; case study on the Thai and British. The study based on cross cultural perception, environmental psychology and design elements of shop window display concept. The photograph of shop window display and questionnaire were used for the research tools. Finally, the research found that Thai and British view the design of window display as a whole as well as its light, colour, composition and theme's concept are the design elements that work as the stimulus to consumers. The consumer's perception was described by 13 bi-polar words. Factor analysis was used to group and reduce variables. The new variables were pleasant/unpleasant and arousing/not arousing that were used for creates a model that describe the consumer feeling on window display identity.
\end{abstract}

Keywords: cross culture, perception, shop window display

\section{Introduction}

Window display is a marketing tool for products presentation and sale promotion. (Edward \& Shackley, 1992) as well as product image promotion. The designing of window display is important since it is the first impression for the passer-by customer. The creativity results for positive behavior of comsumer (Lange et al., 2016). The window display does not only psychologically effect the customer, but also increase sale increate, (Edward \& Shackley, 1992; Chihmin Ti, 2009), store entry, entry decision, (Sen et al., 2002; Oh \& Petric, 2012) and leads to product purchase (Sen et al., 2002).

There are some researches that tried to describe relationship between consumer behavior and window display design by using marketing concept and psychologically acknowledege (Cakrlar, 2010; Lange et al., 2016; Sen et al., 2002) but they are not connect to cross culture. People acknowledgement depend on their background, experience and cultural factor (Segall et al., 1966; Horayangoon, 1983; Matsumot, 1989; Nisbett \& Miyamoto, 2005). Theose factors effect individual norm, thinking, acknowledgemet and decision. In marketing research, cross culture lead to different beheavior of consumer in various areas. The cross culture factor is important to internatonal companies that have to sell their products in many countries since it specifies the product marketing strategy in every single country (Assael, 1984). We can see from the marketing research in cross culture that they are mostly studied in Europe and North America. Besides, the research content, researcher and concept theories are also from the same target groups, for instance, Cultural Dimensions Theory of Hofstede and Edward T. Hall. Apart for that, the marketing research is focused on studying of services and retailing business (Zhang et al., 2008; Mattila \& Patterson, 2004). Even though there are some studies in Asia, they are mostly in China and Japan (Eagele \& brettel, 2011). From this point, it indicades that there are less researches in Asia, especially in Thailand. The cross culture can be devided into 2 groups; Eastern and Western cultures (Mutsumoto, 1999; Nisbett \& Masuda 2003; Kastanakis \& Voyer, 2014). Examples of the cross culture consumer behavior studies are the comparison between American and Korean (Lee \& Ulgado,1997), American, Korean, Chinese and Thai 
consumers (Yeh et al., 1998).

The marketing research on Consumer Behavior model of Kotler 1956; Kotler, 1990 based on Stimulus Response Theory is a classic concept to clarify human behavior. The Psychological factor is also a variable to explain the buyer's characteristic. Kotler explains that the buyers behavior or decision derive from stimulus, such as, promotion, products and environment. At the same time, the studying on Environmental Psychology using Stimulus-Organism-Response Model of Mehrabian and Russell (1974) to explain human behavior and environment. The research concept is that an environment effects human behavior (Gifford, 2007). The popular measurement is Semantic Differential Scale that was developed by Charles E. Osgood (1957) following theories and researches on meaning of words in the sentence represent feeling using short adjective (Ploder \& Eder, 2015) instead of long meaning. In the past decade, the aforementioned concepts are employed to study on the window display environment and found that design factor of the window display has an impact on consumer perception cognition and response (Ti, 2009; Kernsom \& Sahachaisaeree, 2010; Lange et al., 2016; Somoon \& Moorapun, 2016).

However, the context of window display is differ from general environment depends on each type of product, design and location. Each country context has its own character of presentation to suite the customer. In this regards, to study on the said concept to explain the recognition of consumer on window display should be carefully focused on the right measurement method in order to get the suitable measurement to explain the consumer recognition (Dickson \& Albaum, 1977). Besides, there is a cross culture factor involved in import and export of goods due to the convenience transportation system. For example, the United Kingdom, in 2015, the value of investment of the UK in Thailand is approximately 697 Million US Dollars, while the value of Thailand investment in the UK in the same year is 1.3 Billion US Dollars. We can see that Thailand's balance of trade is over 1,273 Million US Dollars. Nevertheless, there are less research on the behavior of cross culture consumer between Thailand and the UK, especially on the identity acknowledgement of window display. The current research found are between Thai and Australian (Jantathai et al., 2014), and Thai and Chinese (Cai \& Shannon, 2012).

In this research, there is a question on "The Evalution on Cross-Culture Consumer Perception to Window Display Indentity". It is to study on the cross culture consumer between Thai and the British in order to evaluate the cross culture consumer perception on window display identity; case study on the Thai and British.

\subsection{Design Elements of Shop Window Display Relate to Perception}

There are some researches on window display perception and behavior of the consumer in various contents, such as, arousal response, character of shop window display, positive behaviors, shopping decision, store entry, product purchase, increasing purchasing behavior (Sen et al., 2002; Ti, 2009; Cakirlar, 2010; Kernsom \& Sahachaisaeree, 2010; Oh \& Petric, 2012; Somoon \& Sahachiseree, 2013; Lange et al., 2016; Somoon \& Moorapun, 2016). The research concept follows Stimulus-Organism-Response Model of Mehrabian and Russell (1974). It views that the window display is one of the psychological stimulus environment on the consumer that response through individual organism. This model is a general model widely employed in both marketing science and environment psychology. The window display is one of the sale environment designed to be a marketing tool to stimulus and attract customer.

From the studies, we learn that design elements effect the consumer's perception, for instance, colour, lighting, mannequin, composition, props, background, graphic, style and object size (Pegler, 1983; Edwards \& Shackley, 1992; White \& White 1996; Derry law 2012; Jeff Clark, 2004; Diamond \& Diamond, 2007; Kernsom \& Sahachaisaeree, 2010; Somoon \& Sahachiseree, 2012; Somoon \& Moorapun, 2016). The concept on design elements of shop window display is applied from composition art the same as architecture, decoration, product design as well as other design works. The aforementioned design elements are carefully and creatively blended together by designer to be according to theme's concept of the product (Diamond \& Diamond, 2007). Even though the window display design should be under the store merchandising concept, image, type of customer and geographic location (Diamond \& Diamond, 2007), but the design element is a vocabulary to specify the structure form of work. It can be applied to all window display designs.

\subsection{Cross-Cultural Perceptions}

People from different culture normally have different social norms, value system (Assael, 1984), thoughts, emotion and attitude since the cultures are by learning, not born to be (Hofstede, 2005). It is part of personal experience and effect their behavior (Horayangoon et al., 2011). According to the cross culture perception and cognition framework proposed by Kastanakis and Voyer (2014) different cultures can be separated broadly into two groups: Western and Eastern. The Eastern are context-independent and their analytic perceptual processes 
focus on object. On the other hand, the Asian tend to be collectivist and holistic. They are interested in the relationship between object and its context (Nisbett \& Miyamoto, 2005). The Eastern are more individualist, independent and low context and their cultures are collectivism, interdependent and high context (Kastanakis \& Voyer, 2014; Mattila \& Patterson, 2004; Nisbett \& Miyamoto, 2005; Nisbett \& Masuda, 2003). Before the word cross cultural plays a role in marketing researches, the word was used in 1930 to compare the different cultures, then developed to be an in-depth studies of each culture. The definition of cross culture comminications was first employed by Edward T.Hall in his publication, the Silent Language (Hall, 1976). The other who is also well accepted is a writer such as Hofstede (1991), the Dutch researcher, who, in the 1980s concluded the theory on culture and argued that Thailand is a high context society, whereas the British is individualist (Hofstede 1991).

\subsection{Meansurmant Scale of Perception}

Perception is part of psychology found by the Gestalt Psychology Group (1912) at the same time as the Behaviorism. The Gestalt focuses on an internal process or personal psychological. They explain that perception is an interpretation of outside stimulus by past experience. They said that individual recognizes in whole, under the concept "the whole is greater than the sum of the parts". In the past, there was an attempt to create personal attitude measurement tools to see their inside their mind. One of the tools used in Psychology is Semantic Differential Scale developed by Charles E. Osgood (1957) applying theories and researches on the meaning of demonstrative word in sentence. He uses a short adjective instead of a long sentence to explain the feeling. The adjective structure comprises of evaluation, potency, and activity. The Semantic Differential Scale of Osgood is to apply two opposite meanings of adjectives (Uzzell \& Romice, 2003) to the testers and see their decision to weight in which direction. In 1969, David R.J. Heise reported that there were more than 1,000 publications on SD. Nowadays, the Semantic Differential scale is a technical measurement standard to measure Social and Behavioral Sciences. The Scale is continued to develop and also apply to used in Marketing Research (Ploder \& Eder, 2015)

\section{Method}

In order to test the hypothesis that How different cultures affect consumers' perception of the window display?, a sample of Thai and UK respondents were selected to make judgments about the meaning of and their preference for a range of shop window displays in the capital cities of London and Bangkok. The present study drew on quantitative and qualitative methods described above to understand the construal of shop window displays by these two consumer groups. A card sorting methodology (Canter et al., 1985) was employed to develop a questionnaire to which responses were quantitative and analyzed by statistical methods. This kind of mixed methodology followed Creswell’s concept (2013)

\subsection{Procedure}

Photos were taken of store window displays in principal shopping streets in Bangkok, and London. From those photos, 60 were selected for use in the sorting task (30 Thai displays and 30 British displays), each of them representing 1 design element (Table 1 ). This research method had an advantage of needing only a small sample group and including interviews that let us interact directly with the participants and get detailed answers to open-ended questions. Participants were asked to sort pictures of shop window displays and interviewed. These sorts were then subject to content analysis.

Table. 1 Conceptualization and operationization variables

\begin{tabular}{cccc}
\hline Conceptual Variables & Operation Variables & & Indicators \\
\hline & & 1 & Warm \\
& Colour & 2 & Cold colour \\
& & 3 & Colourful \\
& & 4 & Monotonous \\
\cline { 2 - 4 } Design elements of shop & Lighting & 5 & Spot Lighting \\
window display & & 6 & Omni Lighting \\
& & 7 & Warm lighting \\
& & 8 & Cold lighting \\
\cline { 2 - 4 } & & 9 & With mannequin \\
& Mannequin & 10 & Without mannequin \\
& & 11 & Abstract mannequin \\
& & 12 & Realistic mannequin \\
\hline
\end{tabular}




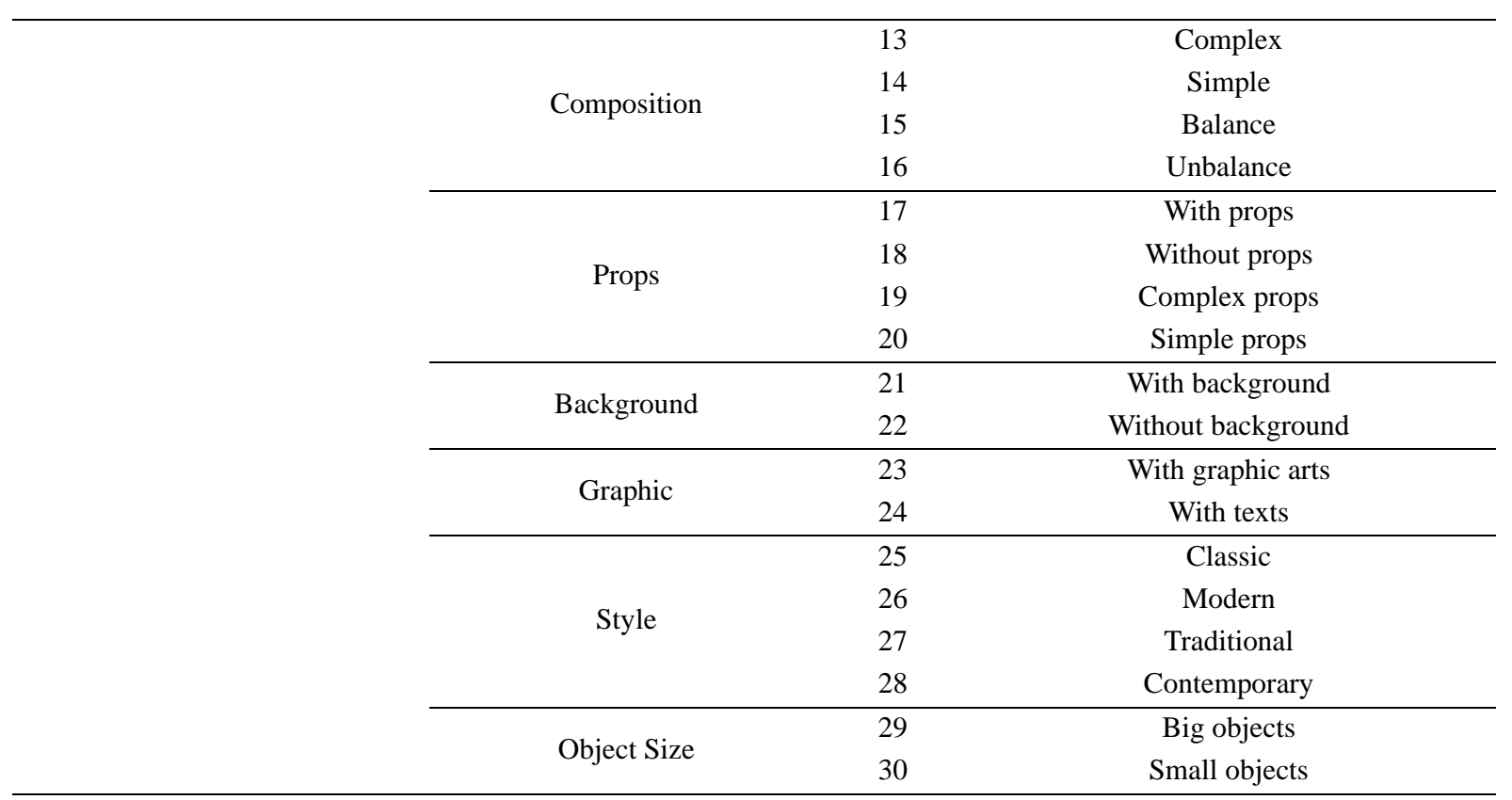

Initially, the sorting task was done by 12 participants all of whom were undergraduate and postgraduate students. Six participants were British. They were studying in England. The other six participants were Thai. They were studying in England and Thailand.

Both the Thai and British participants were asked to undertake two sorts. Firstly an 'open' sort in which they could categorize the groupings in any way they wished. They were then asked to explain the categorization of each group. These descriptions were subsequently used to construct a scale in the questionnaire. They were then asked to sort the photographs into various groups against set criteria (i.e., a structured sort; window displays they like versus window displays they dislike? typically Thai displays versus atypical displays). When they had sorted them into various groups, the respondents was asked to specify why they liked or disliked them, or why they were typically Thai. After sorting, they were interviewed by the author explaining the reasons behind the choices. These answers then provided a number of adjectival descriptors against which all the shop window displays could be assessed. The responses were recorded and screened for inclusion in an online questionnaire.

After the sorting exercise, 8 photographs were selected that represented either typically Thai (4 photograph of shop window display) and typically British (4 photograph of shop window display) store window displays (Table 2). A semantic differential scale based on the responses to the photographs was constructed using opposite descriptors (e.g., colourful - not colorful) (Table 3), a technique widely used in psychological studies (Osgood, 1957). A total of scales were constructed based on 13 pairs of opposite descriptor words. These scales were incorporated into a questionnaire underneath photographs of the 8 window displays, and respondents were asked to rate each window display against all of the rating pairs on a 5 point Likert-type scale (i.e., $1=$ lowest and $5=$ highest).

The second stage of the research involved the construction of an online questionnaire which drew upon the results of the card sorting exercise. The on-line questionnaire was constructed comprising two parts: personal information and a section which required respondents to evaluate the shop window displays. One month after the questionnaire was circulated in Thailand and England, 258 persons had returned the completed questionnaire (114 Thais and 144 Britons).

\subsection{Research tool}

The questionnaire was used as a research tool that contained eight window display photographs and the measurement scale of customer perception towards them, the participants examined these photographs (Table 1) and rated their perception score in the table of paired-opposite words (Table 2).

From 1 to 5 ( 1 = lowest and 5 = highest), scales were constructed based on 13 pairs of opposite feeling words obtained from the sorting task, following the semantic differential scale concept widely used in psychological studies. These scales are shown under the window display photos for the respondents to pick their levels of feeling towards the displays. 
Table 2. Photograph of shop window display

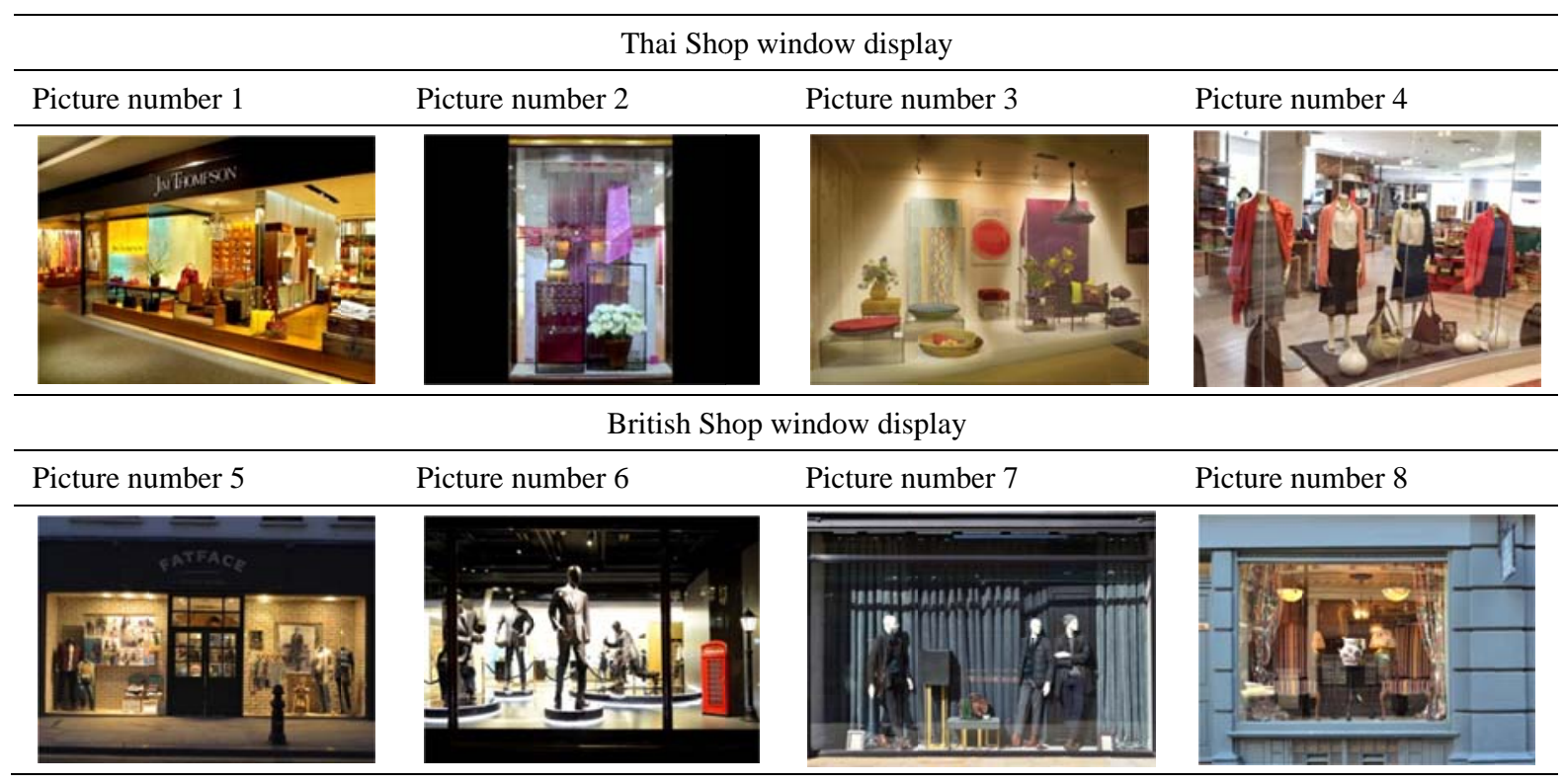

Table 3. The measurement scale of customer perception towards shop window display

\begin{tabular}{|c|c|c|c|c|c|c|c|c|c|c|c|c|}
\hline & & 5 & 4 & 3 & 2 & 1 & 0 & 1 & 2 & 3 & 4 & 5 \\
\hline 1 & Colourful & & & & & & & & & & & Colourless \\
\hline 2 & Well-lit & & & & & & & & & & & Poorly-lit \\
\hline 3 & Expensive & & & & & & & & & & & Cheap \\
\hline 4 & Simple & & & & & & & & & & & Complexity \\
\hline 5 & Relaxing and calming & & & & & & & & & & & exciting+stimulating \\
\hline 6 & Attractive display & & & & & & & & & & & Unattractive display \\
\hline 7 & Impressive & & & & & & & & & & & Unimpressive \\
\hline 8 & Well-arranged & & & & & & & & & & & Poorly arranged \\
\hline 9 & Themed display & & & & & & & & & & & Not themed \\
\hline 10 & Modern & & & & & & & & & & & Old fashioned \\
\hline 11 & Functional & & & & & & & & & & & Decorative \\
\hline 12 & Typically Thai & & & & & & & & & & & Typically British \\
\hline 13 & Strong Identity & & & & & & & & & & & Weak identity \\
\hline
\end{tabular}

\section{Results}

Using factor analysis method, the project groups and reduces the number of variables used to explain the perceptions toward shop window displays to the number possible. A factor analysis on the 13 bi-polar descriptors to form a smaller number of coherent subscales and reduce a large number of related variables to more manageable number (Pallant, 2007). This ensured that the new subcategories comprising similar within-group items which were independent of any other group. The new variables derived from the analysis have been renamed to describe the perceptions of Thais and British easier (Pallant, 2007).

\subsection{Thais'perception analysis}

According to correlation matrix, for the correlation coefficients of .3 and above, the result found that there are 13 variables have a value is less than 0.3 and there are 65 variables is more than 0.3 from all of the 78 variables by correlation. Means that these data can be analyzed according to condition of factor analysis statistic. However, the result show that there are 1 variables not correlation with other variable in the matrix (Pallant, 2007) Therefore, the research was cut out of one variable (Typicaly Thai/Typically British) from the next step of statistical analysis.

The 12 items of the perception scale were subjected to principle components analysis, the suitability of data for factor analysis was assessed. Inspection of the correlation matrix revealed the presence of many coefficients of. 3 
and above. The Kaiser - Meyer - Olkin value was .915, exceeding the recommended value of.6 and Bartlett's Test of Sphericity reached statistical significance, supporting the factorability of the correlation matrix.

Principle components analysis components analysis revealed the presence of two components with eigenvalues exceeding1, explaining $55.9 \%$ and $9 \%$ of the variance respectively. An inspection of the scree plot revealed a clear break after the second component. It was decided to retain two components for further investigation. This was further supported by the results of Parallel analysis, which showed only two components with eigenvalues exceeding the corresponding criterion values for a randomly generated data matrix of the same size.

The two components solution explained a total of $65.19 \%$ of the variance, with component 1 contributing $55.9 \%$ and component 2 contributing 9.3\%. To aid in the interpretation of these two components, Oblimin rotation was performed (Varimax rotation was used to confirm the results again). The rotated solution revealed the presence of simple structure, with both components showing a number of strong loadings and all variable loading substantially on only one component. The results of this analysis support the use of the perception items as separate scale. The research found that the items loading on the two factors with eight items on component 1 , four items loading on component 2. (Table 4)

Table 4. Factor loading of Thai's perception

\begin{tabular}{llllll}
\hline Item & \multicolumn{2}{l}{ Pattern coefficients } & \multicolumn{2}{l}{ Structure coefficients } & Communalities \\
\hline & \multicolumn{2}{l}{ Component 1} & \multicolumn{2}{l}{ Component 2 } & \\
\hline & 1 & 2 & 1 & 2 & .685 \\
\hline 1.9Themed display:Not themed & .891 & & .821 & .360 & .709 \\
1.10Modern:Old fashioned & .867 & & .841 & .427 & .628 \\
1.3Expensive:Cheap & .855 & & .785 & .342 & .814 \\
1.7Impressive:Unimpressive & .846 & & .899 & .560 & .775 \\
1.6Attractive display:Unattractive & .814 & & .875 & .557 & .782 \\
1.8Well-arranged:Poorly arranged & .813 & & .878 & .565 & .609 \\
1.2Well-lit:Poorly-lit & .713 & & .775 & .503 & .523 \\
1.13Strong Identity:Weak identity & .660 & & .718 & .467 & .779 \\
1.5Relaxing:Exciting+stimulating & & .927 & .421 &. $\mathbf{8 8 0}$ & .632 \\
1.11Functional:Decorative & & .792 & .439 & .795 & .559 \\
1.4Simple:Complicated & & .469 & .636 & .677 & .328 \\
1.1Colourful:Colourless & & .432 & .444 & .546 & \\
\hline
\end{tabular}

\subsection{British'perception analysis}

According to correlation matrix, for the correlation coefficients of .3 and above, the result found that there are 33 variables have a value is less than 0.3 and there are 43 variables is more than 0.3 from all of the 78 variables by correlation. Means that these data can be analyzed according to condition of factor analysis statistic. However, the result show that there are 1 variables not correlation with other variable in the matrix (Pallant, 2007) Therefore, the research was cut out of one variable (TypicalyThai/Typically British) from the next step of statistical analysis.

The 12 items of the perception scale were subjected to principle components analysis, the suitability of data for factor analysis was assessed. Inspection of the correlation matrix revealed the presence of many coefficients of.3 and above. The Kaiser - Meyer - Olkin value was .881, exceeding the recommended value of.6 and Bartlett's Test of Sphericity reached statistical significance, supporting the factorability of the correlation matrix.

Principle components analysis components analysis revealed the presence of two components with eigenvalues exceeding1, explaning $44.1 \%, 13.9 \%$ and $8.9 \%$ of the variance respectively. An inspection of the screeplot revealed a clear break after the second component. It was decided to retain two components for further investigation. This was further supported by the serults of Parallel analysis, which showed only two components with eigenvalues exceeding the corresponding criterion values for a randomly generated data matrix of the same size.

The two components solution explaned a total of $66.97 \%$ of the variance, with component 1 contributing $44 \%$ and component 2 contributing 14\%. To aid in the interpretation of these two components, Oblimin rotation was performed (Varimax rotation was used to confirm the results again). The rotated solution revealed the presence of simple structure, with both components showing a number of strong loadings and all variable loading 
substantially on only one component. The results of this analysis support the use of the perception items as separate scale. The research found that the items loading on the two factors with nine items on component 1 , three items loading on component 2. (Table. 5)

Table 5. Factor loading of British’s perception

\begin{tabular}{|c|c|c|c|c|c|}
\hline \multirow[t]{3}{*}{ Item } & \multicolumn{2}{|c|}{ Pattern coefficients } & \multicolumn{2}{|c|}{ Structure coefficients } & \multirow[t]{3}{*}{ Communalities } \\
\hline & \multicolumn{2}{|c|}{ Component 1} & \multicolumn{2}{|c|}{ Component 2} & \\
\hline & 1 & 2 & 1 & 2 & \\
\hline 1.7Impressive:Unimpressive & .894 & & .896 & & .803 \\
\hline 1.6Attractive display:Unattractive & .842 & & .863 & & .754 \\
\hline 1.8Well-arranged:Poorly arranged & .828 & & .864 & .346 & .773 \\
\hline 1.9Themed display:Not themed & .738 & & .740 & & .547 \\
\hline 1.2Well-lit:Poorly-lit & .728 & & .721 & & .521 \\
\hline 1.13Strong Identity:Weak identity & .716 & & .717 & & .514 \\
\hline 1.3Expensive:Cheap & .710 & & .707 & & .500 \\
\hline 1.1Colourful:Colourless & .706 & & .661 & & .477 \\
\hline 1.10Modern:Old fashioned & .437 & & .532 & .531 & .465 \\
\hline 1.4Simple:Complicated & & & & .787 & 622 \\
\hline 1.11Functional:Decorative & & & & .705 & .506 \\
\hline 1.5Relaxing:Exciting+stimulating & & & & .686 & .486 \\
\hline
\end{tabular}

\subsection{Thai and British perception analysis}

According to correlation matrix, for the correlation coefficients of .3 and above, the result found that there are 33 variables have a value is less than 0.3 and there are 43 variables is more than 0.3 from all of the 76 variables by correlation. Means that these data can be analyzed according to condition of factor analysis statistic. However, the result show that there are two variables not correlation with other variable in the matrix (Pallant, 2007) Therefore, the research was cut out of two variable (TypicalyThai/Typically British; 1.10Modern/Old fashioned) from the next step of statistical analysis.

The 11 items of the perception scale were subjected to principle components analysis, the suitability of data for factor analysis was assessed. Inspection of the correlation matrix revealed the presence of many coefficients of .3 and above. The Kaiser - Meyer - Olkin value was .881, exceeding the recommended value of.6 and Bartlett's Test of Sphericity reached statistical significance, supporting the factorability of the correlation matrix.

Principle components analysis components analysis revealed the presence of two components with eigenvalues exceeding1, explaning $44.2 \%$ and $12.8 \%$ of the variance respectively. An inspection of the screeplot revealed a clear break after the second component. It was decided to retain two components for further investigation. This was further supported by the results of Parallel analysis, which showed only two components with eigenvalues exceeding the corresponding criterion values for a randomly generated data matrix of the same size.

The two components solution explaned a total of $62.04 \%$ of the variance, with component 1 contributing $49 \%$ and component 2 contributing 13\%. To aid in the interpretation of these two components, Oblimin rotation was performed (Varimax rotation was used to confirm the results again). The rotated solution revealed the presence of simple structure, with both components showing a number of strong loadings and all variable loading substantially on only one component. The results of this analysis support the use of the perception items as separate scale. The research found that the items loading on the two factors with eight items on component 1 , three items loading on component 2 (Table 6)

Table 6. Factor loading of Thai and British's perception

\begin{tabular}{|c|c|c|c|c|c|}
\hline \multirow[t]{3}{*}{ Item } & \multirow{2}{*}{\multicolumn{2}{|c|}{$\begin{array}{r}\text { Pattern coefficients } \\
\text { Component } 1\end{array}$}} & \multicolumn{2}{|c|}{ Structure coefficients } & \multirow[t]{2}{*}{ Communalities } \\
\hline & & & & nent 2 & \\
\hline & 1 & 2 & 1 & 2 & \\
\hline 1.7Impressive: Unimpressive & .887 & & .899 & .377 & .810 \\
\hline 1.6Attractive display: Unattractive & .828 & & .872 & .453 & .767 \\
\hline 1.8Well-arranged: Poorly arranged & .820 & & .870 & .431 & .775 \\
\hline
\end{tabular}




\begin{tabular}{|c|c|c|c|c|c|}
\hline 1.9Themed display: Not themed & .776 & & .768 & & .590 \\
\hline 1.3Expensive: Cheap & .772 & & .756 & & .555 \\
\hline 1.2Well-lit:Poorly-lit & .755 & & .742 & & .571 \\
\hline 1.13Strong Identity: Weak identity & .715 & & .727 & .309 & .529 \\
\hline 1.1Colourful: Colourless & .652 & & .623 & & .393 \\
\hline 1.5Relaxing: Exciting+stimulating & & .796 & .357 & .815 & .666 \\
\hline 1.4Simple: Complicated & & .784 & .327 & .793 & .622 \\
\hline 1.11Functional: Decorative & & .748 & & .733 & .539 \\
\hline
\end{tabular}

The results suggest that the variables can be groups into two components. The first one is the pleasant/unpleasant dimension of the displays, while the other is the arousing/not arousing dimension of the displays (Table. 7) For the pleasant/unpleasant dimensions, the variables include Impressive/Unimpressive, Attractive display/Unattractive, Well-arranged/Poorly arranged, Themed display/Not themed, Expensive/Cheap, Well-lit/Poorly-lit, Strong Identity/Weak identity and Colourful/Colourless. For the arousing/not arousing dimension, the variables include Relaxing and calming/Exciting+stimulating, Simple/Complex, Functional/decorative, following affective appraisal model by Russell and Lanius (Russell \& Lanius 1984). This research could build the statistical perception model in cross-culture toward window display that was cored in the percepton of pleasant/unpleasant and arousing/not arousing and compound with other perception as shown in Figure 1.

Table 7. New variables

\begin{tabular}{cl}
\hline \multicolumn{1}{c}{ New variable } & \multicolumn{1}{c}{ Perception } \\
\hline & 1.7 Impressive:Unimpressive \\
& 1.6 Attractive display:Unattractive \\
& 1.8 Well-arranged:Poorly arranged \\
Pleasant/Unpleasant & 1.9 Themed display:Not themed \\
& 1.3 Expensive:Cheap \\
& 1.2 Well-lit:Poorly-lit \\
& 1.13 Strong Identity:Weak identity \\
& 1.1 Colourful:Colourless \\
\hline Arousing/not Arousing & 1.5 Relaxing and calming:Exciting+stimulating \\
& 1.4 Simple:Complexity \\
& 1.11 Functional:Decorative \\
\hline
\end{tabular}

\section{Discussion}

Window display is a sale environment that is able to send some menaings to the consumer. It leads to the meanings of visual perception according to Hershberger (1974) idea that environment has presentational meanings that result to responsive meaning. The presentation environment serves as a presentational that conveys the visible character and representational (Hershberger, 1974). For example, product positioning, typically Thai, typically British, identity, cheap or expensive. The responsive meaning creates affective; like or dislike at first sight, evaluating, affective level and prescriptive, that brings the user to action (Hershberger, 1974; Lang, 1979; Gifford, 1987), for instance, decision to enter into shop or to purchase.

We can see from sorting card in the first step that the comsumer from both cultures; the Thai and British view the design of window display as a whole as well as its light, colour composition, and theme's concept is the design elements that work as the stimulus to consumers, (White \& White 1996; Derry law 2012; Clark, 2004; Diamond \& Diamond, 2007; Somoon \& Moorapun 2016) because it is notable and creates the first impression on the customer before the products itself. Customers look at window display and decide from what they see on how impressed or not impressed the store is. The whole concept is the same perception which is contrary to Nisbett and Masuda (2003), who see that people from East and West cultures have different perception. The Eastern culture views things in whole while the Western culture saperate and analyse. Notwithstanding that this study does not against the whole concept of Nisbett \& Masuda (2003), even though they have similar design in basic element study. However, after analyse by studying the most population, we finally found that there are variables that are against each other, they are Colourful: Colourless and Modern:Old fashioned. It is interesting that the 
Thai and British recognize the two variables in opposite way. The Colourful: Colourless emerges from physical environment in Thailand that is sunny for all year long and in Tropical Zone that make the plants and environment colourful and results to the perception of colour different from the British, who are in rainy environment and greyish sky. Meanwhile, for Modern: Old fashioned fector, both countries have totally different dressing cultures and art forms. The British has long history and nationalism, while the Thai always accept the new culture to merge with their existing culture that cause different view of Modern: Old fashioned.

The perception of customer from both cultures to window display identity can be explained in short words instead of long sentences. The words can also be used to create perception measurement to measure the cross-culture window display identity by using semantic differential scale (Osgood, 1957). The window display measurement scale derives from this research comprises of 13 opposit pair words. When considers in details of all words in the scale, the words receive from cross culture consumer recognition on window display are in accorcance with design elements and aesthetic judgement (Berlyne 1974). This concept is in consistence with Vimolsiddhi Horayangkura's Concept on basic principle that the principle of design is actually from psychological acknowledge concept since the design work on aesthetics of percpective depends on individual acknowledge. However, in the past, we cannot assume that the developed basic principle of design depends on psychological recognition theory to support the principle (Horayankura et al., 2011).

We can find in this research that there are words that relate to the window design principle, for instance, colourful, colourless, well-lit, poorly-lit, well-arranged, poorly arranged, themed display and not themed. In terms of the Aesthetic Judgment, thery are, for example, attractive display, unattractive display, impressive, unimpressive relaxing+calming, exciting+stimulating and simple, complicated which is in consistence of the aesthetic judgement concept consisting 2 Dimensions; uncertainty arousal and hedonic tone (Berlyne 1974). They both play important roles of aesthetic judgement comprising; Complexity, Novelty, Incongruity and Surprisingness (Berlyne, 1960). Besides, other words for window display judgement is in accordance with Affective Appraisal model that is developed and employed to measure psychological judgement on environment acknowledge (Russell and Lanius 1984). Its core composition are pleasant/unpleasant and arousing/not arousing. Each core has sub-wordings that explain the feeling against physical environment. When comparing the said model with the words analysing from the cross culture consumer. It is interesting that the words reflect emotion and feeling closer to Russell and Lanius Concept. The research creates a model that describe the consumer feeling on window display identity (Figure 1).

The benefit of this research can be devided into three points. Firstly, Benefit for designer to help communicating between the designer and user in terms of meanings and beauty (Sahachaisaeree, 2011) that is able to read the consumers' mind that the configuration in each design is important, especially, the use of colours, lighting and composition which are the main element that the consumer always mention when appreciate the window display. The good and creative design result to positive attitude towards the product and design. The research for design is considered part of design process (Sahachaisaeree, 2011). It is also an alternative decision for the next design. Secondly, it is beneficial for marketing research in terms of understandering the impression and behavior of consumer, especially from different cultures. The scale can be employed to judgement after finished shop decoration in order to see feedback from the customer. It also makes the marketing plan easier in selling strategies and product positioning to response to the customer's need, as well as to know which design that enhance the product image and increase the sales. Thirdly, it is beneficial for design research and increase knowledge and experience in window display perception model in Reseach Science and Design. The research integrates marketing, environmental psychology and design principle together.

There are three points instruction for future research. Firstly, the cross culture study in Asian countries is interesting since the countries have constantly selling and purchasing goods. Nevertheless, the consumer behavior in each country is different from each other. For example, Thai and Myanmar and, Thai and Japanese customers. Secondly, the perception measurement should be simulated or tested on actual window display to compare between the simulation and existent environment. Thirdly, the different judgement in Colourful:Colourless and Modern:Old fashioned between Thai and British is a remarkable issue for the future research. 


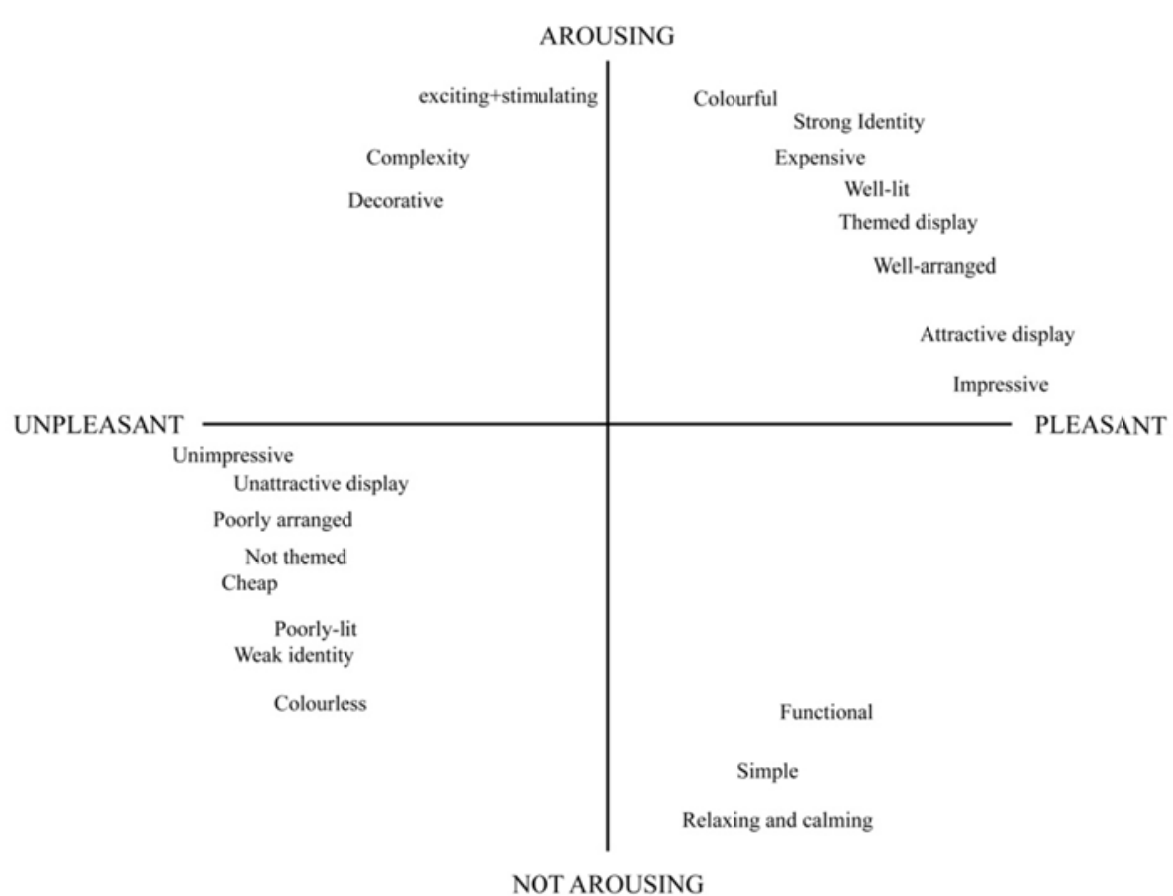

Figure 1. Perception of shop window display model

\section{Acknowledgments}

Financial support from the Thailand Research Fund through the Royal Golden Jubilee Ph.D. Program and King Mongkut's Institute of Technology Ladkrabang are gratefully acknowledged. I would like to express my gratitude to my co-supervisor, Prof. David Uzzell whose expertise greatly assisted the success of this research. I would also like to thank Dr. Birgitta Gatersleben for her valuable advice and guidance on statistics and methodology of the study.

\section{References}

Cai, Y., \& Shannon, R. (2012). Personal values and mall shopping behavior: The mediating role of attitude and intention among Chinese and Thai consumers. Australasian Marketing Journal (AMJ), 20(1), 37-47. https://doi.org/10.1016/j.ausmj.2011.10.013

Cakırlar, Y. B. (2010). Factors affecting evaluations of storefront designs and inferences on store characteristics (Master ’s thesis, Bilkent University, Ankara Turkey). Retrieved from http://hdl.handle.net/11693/15093

Canter, D., Brown, J., \& Groat, L. N. (1985). The multiple sorting task. The Research Interview.

Assael, H. (1984). Consumer behavior and marketing action. Kent Pub. Co.

Berlyne, D. E. (1974). Studies in the new experimental aesthetics: Steps toward an objective psychology of aesthetic appreciation. Hemisphere.

Berlyne, D. E. (1960). Conflict, arousal, and curiosity. https://doi.org/10.1037/11164-000

Diamond, J., \& Diamond, E. (2007). Contemporary visual merchandising and environmental design (4th ed.). Upper Saddle River, NJ.

Dickson, J., \& Albaum, G. (1977). A method for developing tailormade semantic differentials for specific marketing content Areas. Journal of Marketing Research, 14(1), 87. https://doi.org/10.2307/3151058

Edwards, S., \& Shackley, M. (1992). Measuring the effectiveness of retail window display as an element of the marketing mix. International Journal of Advertising, 11(3), 193-202. https://doi.org/10.1080/02650487.1992.11104494

Engelen, A., \& Brettel, M. (2011). Assessing cross-cultural marketing theory and research. Journal of Business Research, 64(5), 516-523. https://doi.org/10.1016/j.jbusres.2010.04.008 
Gifford, R. (2007). Environmental psychology: Principles and practice (p. 372). Colville, WA: Optimal books.

Gifford, R., Hine, D. W., Muller-Clemm, W., Reynolds, D. J., \& Shaw, K. T. (2000). Decoding modern architecture. Environment and Behavior, 32(2), 163-187. https://doi.org/10.1177/00139160021972487

Groat, L., \& Wang, D. (2002). Architectural research methods. New York.

Horayangoon, W. (1983). Environmental and behaviour. Chulalongkorn University. Bangkok.

Horayangoon. W., Setworrakit, B., \& Klinmalai, S. (2011). Environmental and behaviour. GBP center. Bangkok.

Jantathai, S., Sungsri-in, M., Mukprasirt, A., \& Duerrschmid, K. (2014). Sensory expectations and perceptions of Austrian and Thai consumers: A case study with six colored Thai desserts. Food Research International, 64, 65-73. https://doi.org/10.1016/j.foodres.2014.06.007

Kastanakis, M. N., \& Voyer, B. G. (2014). The effect of culture on perception and cognition: A conceptual framework. Journal of Business Research, 67(4), 425-433. https://doi.org/10.1016/j.jbusres.2013.03.028

Kernsom, T., \& Sahachaisaeree, N. (2010). Determinant of design elements and compositional settings of window display on the corporate strategic merchandising of large scale department store: a case of central world department store. Procedia - Social and Behavioral Sciences, 5, 1351-1356. https://doi.org/10.1016/j.sbspro.2010.07.286

Kotler, P. (1965). Behavioral models for analyzing buyers. Journal of Marketing, 29(4), 37. https://doi.org/10.2307/1249700

Kotler, P., Armstrong, G., Franke, G., \& Bunn, M. D. (1990). Marketing: an introduction (Vol. 1). Prentice-Hall.

Lange, F., Rosengren, S., \& Blom, A. (1016) .Store-window creativity's impact on shopper behavior. Journal of Business Research, 69(3), 1014-1021. https://doi.org/10.1016/j.jbusres.2015.08.013

Lee, M., \& Ulgado, F. M. (1997). Consumer evaluations of fast-food services: a cross-national comparison. Journal of Services Marketing, 11(1), 39-52. https://doi.org/10.1108/08876049710158358

Mattila, A. S., \& Patterson, P. G. (2004). The impact of culture on consumers? perceptions of service recovery efforts. Journal of Retailing, 80(3), 196-206. https://doi.org/10.1016/j.jretai.2004.08.001

Mehrabian, A., \& Russell, J. A. (1974). An approach to environmental psychology. Cambridge, Mass.: MIT Press.

Morgan, T. (2008). Visual merchandising: Window and in-store displays for retail. Laurence king publishing ltd.

Matsumoto, D. (1989). Cultural influences on the perception of emotion. Journal of cross-cultural psychology, 20(1), 92-105. https://doi.org/10.1177/0022022189201006

Matsumoto, D. (1999). Culture and self: An empirical assessment of Markus and Kitayama's theory of independent and interdependent self-construals. Asian Journal of Social Psychology, 2(3), 289-310. https://doi.org/10.1111/1467-839x.00042

Nisbett, R. E., \& Miyamoto, Y. (2005). The influence of culture: holistic versus analytic perception. Trends in Cognitive Sciences, 9(10), 467-473. https://doi.org/10.1016/j.tics.2005.08.004

Nisbett, R. E., \& Masuda, T. (2003). Culture and point of view. Proceedings of the National Academy of Sciences, 100(19), 11163-11170. https://doi.org/10.1073/pnas.1934527100

Oh, H., \& Petrie, J. (2012). How do storefront window displays influence entering decisions of clothing stores? Journal of Retailing and Consumer Services, 19(1), 27-35. https://doi.org/10.1016/j.jretconser.2011.08.003

Osgood, Ch. E., Suci, G., Tannenbaum, P. (1957). The Measurement of Meaning. University of Illinois Press, Urbana.

Pallant, J. (2007). SPSS survival manual: A step-by-step guide to data analysis using SPSS version 15. Nova Iorque: McGraw Hill.

Pegler, M. M. (1983). Visual merchandising and display. Fairchild Publications.

Ploder, A., \& Eder, A. (2015). Semantic Differential. International Encyclopedia of the Social \& Behavioral Sciences, 563-571. https://doi.org/10.1016/b978-0-08-097086-8.03231-1

Russell, J. A., \& Lanius, U. F. (1984). Adaptation level and the affective appraisal of environments. Journal of Environmental Psychology, 4(2), 119-135. https://doi.org/10.1016/s0272-4944(84)80029-8

Sahachaisaeree, N. (2012). Environmental simulation and behavioral response as means of enquiry in 
multidisciplinary design research procedure. Procedia - Social and Behavioral Sciences, 36, 35-50. https://doi.org/10.1016/j.sbspro.2012.03.005

Segall, M. H., Campbell, D. T., \& Herskovits, M. J. (1966). The influence of culture on visual perception. Indianapolis: Bobbs-Merrill.

Sen, S., Block, L. G., \& Chandran, S. (2002). Window displays and consumer shopping decisions. Journal of Retailing and Consumer Services, 9(5), 277-290. https://doi.org/10.1016/s0969-6989(01)00037-6

Somoon, K., \& Sahachaisaree, N. (2012). Design Elements and Users’ Perceptual Response: A Case of Window Display Design for Adolescent Merchandising. Procedia - Social and Behavioral Sciences, 50, 685-690. https://doi.org/10.1016/j.sbspro.2012.08.071

Somoon, K., \& Moorapun, C. (2016). The Roles of aesthetic and cultural perception affected by window display of thai crafts products to increase purchasing intention. Procedia - Social and Behavioral Sciences, 234, 55-63. https://doi.org/10.1016/j.sbspro.2016.10.219

Son, J.-S., Do, V. B., Kim, K.-O., Cho, M. S., Suwonsichon, T., \& Valentin, D. (2013). Consumers' attitude towards rice cooking processes in Korea, Japan, Thailand and France. Food Quality and Preference, 29(1), 65-75. https://doi.org/10.1016/j.foodqual.2013.02.002

Uzzell DL. and Romice O. (2003) 'L'analyse des expériences environnementales' in G. Moser and K. Weiss (Eds.) Espaces de vie/Aspects de la relation homme-environnement Paris/A. Colin pp 49-84

White, K., \& White, F. (1996). Display \& Visual Merchandising. St. Francis Press.

Yeh, L. ., Kim, K. ., Chompreeda, P., Rimkeeree, H., Yau, N. J., \& Lundahl, D. (1998). Comparison in use of the 9-point hedonic scale between Americans, Chinese, Koreans, and Thai. Food Quality and Preference, 9(6), 413-419. https://doi.org/10.1016/s0950-3293(98)00028-7

Zhang, J., Beatty, S. E., \& Walsh, G. (2008). Review and future directions of cross-cultural consumer services research. Journal of Business Research, 61(3), 211-224. https://doi.org/10.1016/j.jbusres.2007.06.003

\section{Copyrights}

Copyright for this article is retained by the author(s), with first publication rights granted to the journal.

This is an open-access article distributed under the terms and conditions of the Creative Commons Attribution license (http://creativecommons.org/licenses/by/4.0/). 